\title{
The Influence of Protonation on the Electroreduction of Bi (III) Ions in Chlorates (VII) Solutions of Different Water Activity
}

\author{
Agnieszka Nosal-Wiercińska • Mariusz Grochowski • \\ Malgorzata Wiśniewska • Katarzyna Tyszczuk-Rotko • \\ Slawomira Skrzypek • Mariola Brycht • \\ Dariusz Guziejewski
}

Published online: 24 February 2015

(C) The Author(s) 2015. This article is published with open access at Springerlink.com

\begin{abstract}
We examined the electroreduction of Bi (III) ions in chlorate (VII) solutions under varied protonation conditions of the depolariser using voltammetric and impedance methods. The results of the kinetic parameter correlation lead to the statement that the changes in the amount of chloric (VII) acid against the amount of its sodium salt in the supporting electrolytes of the low water activity have a significant influence on the rate of $\mathrm{Bi}$ (III) ion electroreduction. The increase of the concentration of chloric acid sodium salt, as well as the chloric (VII) acid alone within the particular concentration of the supporting electrolyte, inhibits the process of Bi (III) ion electroreduction. It should be associated with the reorganisation of the structure of the double layer connected with the slow dehydration inhibited by $\mathrm{ClO}_{4}^{-}$ions. The standard rate constants $k_{\mathrm{s}}$ values with the increase of the chlorate (VII) concentrations for all the solutions examined of chlorates (VII) confirms the catalytic influence of the decrease of water activity on the process of $\mathrm{Bi}$ (III) ion electroreduction. The multistage process is confirmed by the non-rectilinear $\ln k_{\mathrm{f}}=f(E)$ dependences.
\end{abstract}

\footnotetext{
A. Nosal-Wiercińska $(\square) \cdot$ M. Grochowski $\cdot K$. Tyszczuk-Rotko Faculty of Chemistry, Department of Analytical Chemistry and Instrumental Analysis, M. Curie-Skłodowska University, M.

Curie-Skłodowska Sq. 3, 20-031 Lublin, Poland

e-mail: anosal@poczta.umcs.lublin.pl

M. Wiśniewska

Faculty of Chemistry, Department of Radio Chemistry and Colloid Chemistry, M. Curie-Skłodowska University, M. Curie-Skłodowska Sq. 3, 20-031 Lublin, Poland
}

S. Skrzypek $\cdot$ M. Brycht $\cdot$ D. Guziejewski

Faculty of Chemistry, Department of Inorganic and Analytical Chemistry, University of Łódź, Tamka 12 Sq, 90-236 Łódź, Poland
Keywords Electrochemistry · Bi (III) electroreduction . Protonation $\cdot$ Double layer $\cdot$ Kinetic parameters $\cdot$ Catalytic activity

\section{Introduction}

The electrochemical properties of metal ions depend on the composition and concentration of the supporting electrolyte. The metal cations in aqueous solutions show strong interactions with water molecules. The dehydration steps play a big role in the deposition reactions [1].

The studies concerning the reduction process of $\mathrm{Bi}$ (III) in chlorates (VII) solution of different water activity point at strong interactions between a depolariser ion and water molecules $[2,3]$.

The hydrolysis of $\mathrm{Bi}$ (III) ions reduces the $\mathrm{pH}$ range in which you can study their electroreduction. It has to be emphasised that aqua ions $\left[\mathrm{Bi}\left(\mathrm{H}_{2} \mathrm{O}\right)_{9}\right]^{+3}$ only exist in strongly acidic noncomplexing solutions. In solutions with $\mathrm{pH}>0$, oxo and hydroxo complexes of $\mathrm{BiOH}^{+2}, \mathrm{Bi}(\mathrm{OH})_{2}^{+}$and $\mathrm{BiO}_{\mathrm{aq}}^{+}$or condensed structures such as $\mathrm{Bi}_{2} \mathrm{O}^{+4}, \mathrm{Bi}_{6} \mathrm{O}_{6}^{+6}, \mathrm{Bi}_{6}(\mathrm{OH})_{4}^{+6}$, and $\mathrm{Bi}_{6} \mathrm{O}_{6}(\mathrm{OH})_{3}^{+3}[1]$.

According to Lovrič et al., [3] the reduction of Bi (III) includes three partial dehydration steps. Additionally, in the first stage of $\mathrm{Bi}$ (III) electroreduction, the cations of the supporting electrolyte participate and they absorb as well the released water molecules in their hydration spheres, which can explain the inversely proportional dependence of the reaction rate on water activity. The studies conducted in $1-8 \mathrm{~mol} \mathrm{dm}^{-3}$ chlorates (VII) [4] point at the significant role of water activity in the Bi (III) electroreduction process. The values of kinetic parameters determined in the examined solutions point at the 
slight influence of supporting electrolyte concentration on the kinetics of $\mathrm{Bi}$ (III) electroreduction in $1-3 \mathrm{~mol} \mathrm{dm}^{-3}$ chlorates (VII), whereas in 4-8 $\mathrm{mol} \mathrm{dm}^{-3}$ chlorates (VII) the values of the determined kinetic parameters indicate a significant increase of reversibility of $\mathrm{Bi}$ (III) ion electroreduction, with the increase of chlorates (VII) concentration. The character of the changing rate of constants, in the function of the potential, indicates at a multistage process of $\mathrm{Bi}$ (III) ions electroreduction, as well as a different mechanism of $\mathrm{Bi}$ (III) electroreduction in the solutions with low water activity in comparison with the solutions with high water activity [4].

The subject matter of the research will be the electroreduction of $\mathrm{Bi}$ (III) ions in chlorates (VII). The issue of Bi (III) ion electroreduction in weak complexing solutions entails the aspect of practical research. Mainly the possibility of directing and pointing towards increased accuracy of $\mathrm{Bi}$ (III) ion determination.

In the experiments, the chloric (VII) acid to sodium chlorate (VII) concentration ratios in the supporting electrolyte were varied, leading to various forms of the studied depolariser.

The methodology of the study is based on the electrochemical methods (voltammetry, Faradaic impedance).

\section{Experimental}

\section{Technique of Measurement}

The measurements were performed in a three-electrode cell containing the following: a dropping or hanging mercuryelectrode with a controlled increase rate and a constant drop surface $\left(0.014740 \mathrm{~cm}^{2}\right)$, as a working electrode (MTM Poland); $\mathrm{Ag} / \mathrm{AgCl}$ as a reference electrode and a platinum spiral, as an auxiliary electrode. The polarographic, voltammetric and impedance measurements were carried out in thermostated cells at $298 \mathrm{~K}$ by using an Autolab Fra 2/GPES (Version 4.9) frequency response analyser (Eco Chemie, Utrecht, Netherlands). The solutions were deaerated using nitrogen, which was passed over the solutions during the measurements. Analytical grade chemicals from Fluka were used.

The 2-7 mol dm${ }^{-3}$ chlorates (VII) solutions of concentration ratio $\mathrm{HClO}_{4}: \mathrm{NaClO}_{4}$ such as (1:1) solution $\mathrm{A}$, (1:4) solution $\mathrm{B},(1: 9)$ solution $\mathrm{C},(4: 1)$ solution $\mathrm{D},(9: 1)$ solution $\mathrm{E}$ were studied.

The enumerated solutions were designated according to the scheme, e.g.

3A Designates $3 \mathrm{~mol} \mathrm{dm}^{-3}$ chlorates (VII), where $\mathrm{HClO}_{4}$ : $\mathrm{NaClO}_{4}=1: 1$

3B Designates $3 \mathrm{~mol} \mathrm{dm}^{-3}$ chlorates (VII), where $\mathrm{HClO}_{4}$ : $\mathrm{NaClO}_{4}=1: 4$
3C Designates $3 \mathrm{~mol} \mathrm{dm}{ }^{-3}$ chlorates (VII), where $\mathrm{HClO}_{4}$ : $\mathrm{NaClO}_{4}=1: 9$

3D Designates $3 \mathrm{~mol} \mathrm{dm}^{-3}$ chlorates (VII), where $\mathrm{HClO}_{4}$ : $\mathrm{NaClO}_{4}=4: 1$

3E Designates $3 \mathrm{~mol} \mathrm{dm}^{-3}$ chlorates (VII), where $\mathrm{HClO}_{4}$ : $\mathrm{NaClO}_{4}=9: 1$

The concentration of $\mathrm{Bi}$ (III) ions in the solutions studied was always $110^{-3} \mathrm{~mol} \mathrm{dm}^{-3}$. Due to the weak solubility of Bi $\left(\mathrm{NO}_{3}\right)_{3}$ in chlorates (VII), the solutions were sonicated.

In the DC polarography, SWV and CV voltammetry, the optimal experimental operating conditions were as follows: step potential $2 \mathrm{mV}$ for DC, puls amplitude $20 \mathrm{mV}$, frequency $120 \mathrm{~Hz}$ and step potential $2 \mathrm{mV}$ for SWV, and scan rate 5$1000 \mathrm{mVs}^{-1}$ and step potential $5 \mathrm{mV}$ for CV. Impedance data were collected at 24 frequencies in the range from 200 to 50 , $000 \mathrm{~Hz}$ within the faradaic potential region at $10 \mathrm{mV}$ intervals.

\section{Elaboration of Experimental Data}

The approximate diffusion coefficient $\left(D_{\text {ox }}\right) \mathrm{Bi}$ (III) ions in the studied solutions were calculated using the Ilkovič equation for diffusion-controlled limiting current. The DC waves of $\mathrm{Bi}$ (III) in 1-8 $\mathrm{mol} \mathrm{dm}^{-3}$ chlorates (VII) solutions were used as a standard [4]. The formal potentials $\left(E_{\mathrm{f}}^{0}\right)$ of the electrode processes and values of the kinetic parameters $\left(\alpha n_{\alpha}\right.$ and $\left.k_{\mathrm{s}}\right)$ were calculated based on voltammetric measurements. The details are described elsewhere [4]. According to the reversibility parameter of the electrode process (based on the dependence of the potential difference of anodic $E_{\mathrm{pa}}$ and cathodic $E_{\mathrm{pc}}$ peaks on the value $0.057 / n$ ), the standard rate constants $k_{\mathrm{s}}$ were determined using two different equations. For the quasi-reversible processes, the $k_{\mathrm{s}}$ values were determined using the method elaborated by Nicholson [5] according to the equation:

$\Psi=\left(\frac{D_{\mathrm{ox}}}{D_{\mathrm{red}}}\right)^{\alpha / 2} \frac{k_{\mathrm{s}}(\mathrm{R} T)^{1 / 2}}{\left(\pi n \mathrm{~F} v D_{\mathrm{ox}}\right)^{1 / 2}}$

The function $\psi$ was determined from the product of electron number exchanged in the electrode process $(n)$ and the difference between the potentials of anodic and cathodic peaks $\left(E_{\mathrm{pa}}-E_{\mathrm{pc}}\right)$, and its dependence on $n\left(E_{\mathrm{pa}}-E_{\mathrm{pc}}\right)$ was tabled [6].

For the irreversible processes, the values $k_{\mathrm{s}}$, which are dependent on the kinetic parameters, are described by the equation [4]:

$E_{\mathrm{pc}}=E_{\mathrm{f}}^{0}-\frac{\mathrm{R} T}{\alpha n_{\alpha} \mathrm{F}}\left[0.78-\ln k_{\mathrm{s}}+\ln \sqrt{D_{\mathrm{ox}} b}\right]$ 
where:

$b=\frac{\alpha n_{\alpha} \mathrm{F} v}{\mathrm{R} T}$.

The values of the apparent rate constants $k_{\mathrm{f}}$ of $\mathrm{Bi}$ (III) ion electroreduction in the chlorates (VII) solutions as a function of the potential were calculated from impedance measurements. The details are described elsewhere [4].

\section{Results and Discussion}

Polarographic and Voltammetric Measurements

Figure 1 presents SWV peaks of Bi (III) electroreduction in 2$7 \mathrm{~mol} \mathrm{dm}^{-3}$ chlorates (VII), of the concentration ratio $\mathrm{HClO}_{4}$ : $\mathrm{NaClO}_{4}=1: 1$. With the increase of chlorates (VII) concentration, the SWV peaks of Bi (III) increase and are shifted towards the positive potentials. These results are inversely proportional to the water activity. These changes are practically identical with the results obtained in the earlier work, which points to the fact that the replacement of half of the chloric (VII) acid by the sodium chlorate (VII) has no influence on the height and position of the peaks.

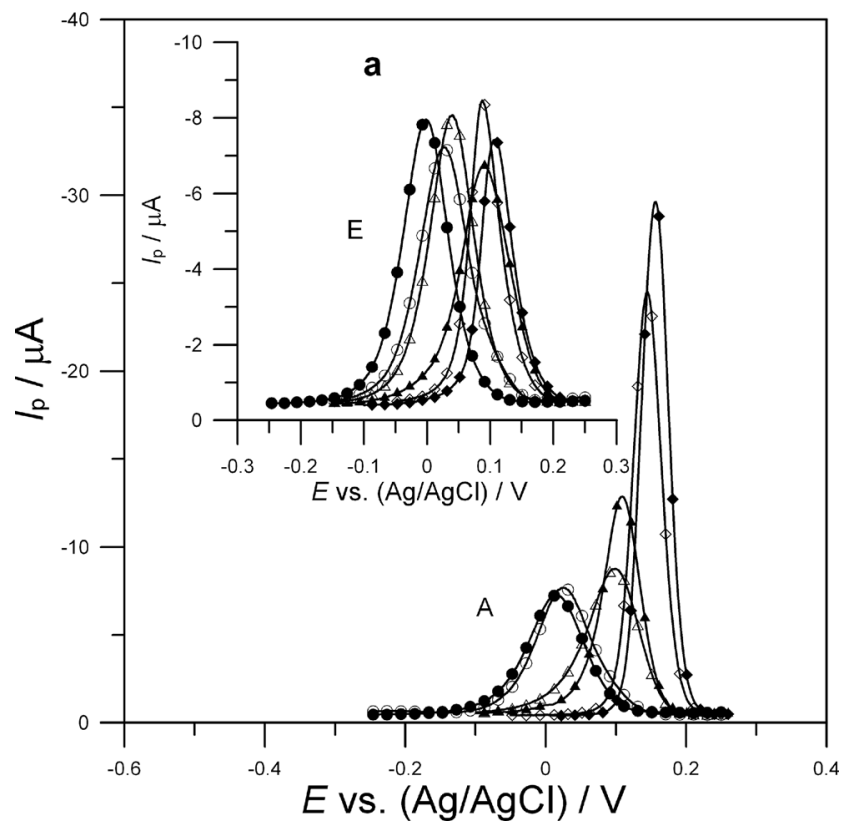

Fig. 1 The SWV peaks of the electroreduction of $110^{-3} \mathrm{~mol} \mathrm{dm}^{-3} \mathrm{Bi}$ (III) in 2-7 mol dm${ }^{-3}$ chlorates (VII), where $\mathrm{HClO}_{4}: \mathrm{NaClO}_{4}=1: 1(A)$. The concentration of chlorates (VII) in mol dm${ }^{-3}$ : (०) $2 ;(\bullet) 3 ;(\Delta) 4 ;(\boldsymbol{\Delta})$

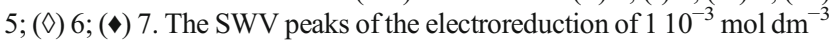
$\mathrm{Bi}$ (III) in 2-7 mol dm${ }^{-3}$ chlorates (VII), where $\mathrm{HClO}_{4}: \mathrm{NaClO}_{4}=9: 1(E)$. The concentration of chlorates (VII) in mol dm${ }^{-3}:(\circ) 2 ;(\bullet) 3 ;(\Delta) 4 ;(\boldsymbol{\Delta})$ $5 ;(\diamond) 6 ;(\diamond) 7$
Figure 1a presents SWV peaks of Bi (III) electroreduction in $2-7 \mathrm{~mol} \mathrm{dm}^{-3}$ chlorates (VII), but at the concentration ratio $\mathrm{HClO}_{4}: \mathrm{NaClO}_{4}=9: 1$. The changes of the peak potentials of $\mathrm{Bi}$ (III) electroreduction are similar to those in Fig. 1. It suggests that the composition of the active complex is independent on the concentration ratio $\mathrm{HClO}_{4}$ and $\mathrm{NaClO}_{4}$; whereas the peaks' height is practically unchanged with the change of chlorates (VII) concentration, which points to the fact that in the solutions with a large excess of chloric (VII) acid in comparison with sodium chlorate (VII), the rate of $\mathrm{Bi}$ (III) ion electroreduction is practically independent from the chlorate (VII) concentration.

In Fig. 2a, the dependences of SWV electroreduction peaks of $110^{-3} \mathrm{~mol} \mathrm{dm}^{-3} \mathrm{Bi}$ (III) in $3 \mathrm{~mol} \mathrm{dm}^{-3}$ chlorates (VII) (Fig. 2) and in $7 \mathrm{~mol} \mathrm{dm}^{-3}$ chlorates (VII) (Fig. 2a) of the concentration ratios $\mathrm{HClO}_{4}: \mathrm{NaClO}_{4}: 1$ (A); 1:4 (B); 1:9 (C); 4:1 (D); 9:1 (E) were shown. In $3 \mathrm{~mol} \mathrm{dm}^{-3}$ chlorates (VII), the changes in the concentration ratios $\mathrm{HClO}_{4}: \mathrm{NaClO}_{4}$ do not significantly influence the course of the curves $I_{\mathrm{p}}=\mathrm{f}(E)$. How-

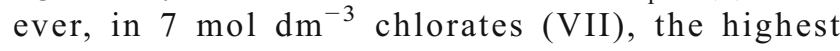
electroreduction peaks of $\mathrm{Bi}$ (III) are observed at $\mathrm{HClO}_{4}$ : $\mathrm{NaClO}_{4}=1: 1$. The increase of $\mathrm{NaClO}_{4}$ concentration in the supporting electrolyte causes the decrease of the peak (Fig. 2, curves B, C) and the shift towards the positive potentials. The increase of $\mathrm{HClO}_{4}$ concentration in chlorates (VII) solution (Fig. 2 curves D, E) causes the further decrease of

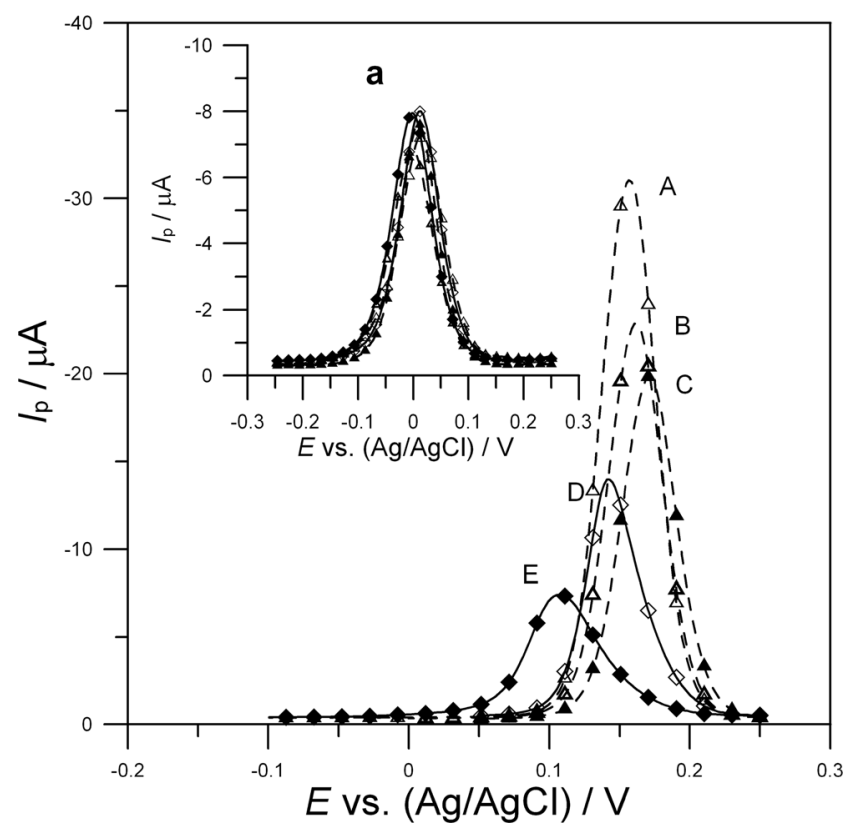

Fig. 2 The SWV peaks of the electroreduction of $110^{-3} \mathrm{~mol} \mathrm{dm}^{-3} \mathrm{Bi}$ (III) in $7 \mathrm{~mol} \mathrm{dm}^{-3}$ chlorates (VII), where $\mathrm{HClO}_{4}: \mathrm{NaClO}_{4}=1: 1(-) 7 \mathrm{~A}$; $\mathrm{HClO}_{4}: \mathrm{NaClO}_{4}=1: 4(-) 7 \mathrm{~B} ; \mathrm{HClO}_{4}: \mathrm{NaClO}_{4}=1: 9$ (一) 7C; $\mathrm{HClO}_{4}$ : $\mathrm{NaClO}_{4}=4: 1(-)$ 7D; $\mathrm{HClO}_{4}: \mathrm{NaClO}_{4}=9: 1(-)$ 7E. The SWV peaks of the electroreduction of $110^{-3} \mathrm{~mol} \mathrm{dm}^{-3} \mathrm{Bi}$ (III) in $3 \mathrm{~mol} \mathrm{dm}^{-3}$ chlorates (VII), where $\mathrm{HClO}_{4}: \mathrm{NaClO}_{4}=1: 1(-) 3 \mathrm{~A} ; \mathrm{HClO}_{4}: \mathrm{NaClO}_{4}=1: 4(-) 3 \mathrm{~B}$; $\mathrm{HClO}_{4}: \mathrm{NaClO}_{4}=1: 9(-) 3 \mathrm{C} ; \mathrm{HClO}_{4}: \mathrm{NaClO}_{4}=4: 1$ (-) 3D; $\mathrm{HClO}_{4}$ : $\mathrm{NaClO}_{4}=9: 1(-) 3 \mathrm{E}$ 
SWV peaks of Bi (III) ions electroreduction, whereas the peak potential is shifted towards the more negative potentials. This suggests that the increase of $\mathrm{HClO}_{4}$ concentration (curves D and E) causes significant changes in the composition of the active complex, which implicates the decrease of the rate of the $\mathrm{Bi}$ (III) ions electroreduction process.

The possibility of the formation of ionic pairs, e. g. Bi (III) $-\mathrm{ClO}_{4}^{-}$has to be mentioned. If the electrode surface is charged negatively, the ionic pairs can favour decreasing the electroreduction rate [7].

The influence of water activity on the Bi (III) electroreduction process in $\left(2-7 \mathrm{~mol} \mathrm{dm}^{-3}\right)$ chlorates (VII) for different content of $\mathrm{NaClO}_{4}$ and $\mathrm{HClO}_{4}$ also results from the course of the chronovoltammetric curves CV (Fig. 3a). With the increase of the chlorates (VII) concentration from 2 to $7 \mathrm{~mol} \mathrm{dm}^{-3}$ in the solutions $\mathrm{A}, \mathrm{B}$ and $\mathrm{C}$ of the supporting electrolytes, the decrease of $\Delta E_{\mathrm{ac}}$ between the anodic and cathodic peaks is observed, which testifies to the increase of the reversibility of $\mathrm{Bi}$ (III) electroreduction process. Whereas for the solutions $\mathrm{D}$ and $\mathrm{E}$, where the dominance of $\mathrm{HClO}_{4}$ acid against $\mathrm{NaClO}_{4}$ is increasing, the changes of $\Delta E_{\mathrm{ac}}$ with the decrease of water activity are low.

Figure 4 presents CV curves of Bi (III) ions electroreduction in $6 \mathrm{~mol} \mathrm{dm}^{-3}$ chlorates (VII), but for the different content of chloric acid and its sodium salt (6A, 6B, $6 \mathrm{C}, 6 \mathrm{D}, 6 \mathrm{E})$. It should be noted that the anodic peaks of $\mathrm{Bi}$ (III) ions electroreduction are higher comparing to the cathodic peaks. The potentials of cathodic and anodic peaks are shifted towards the more positive potentials with the increase

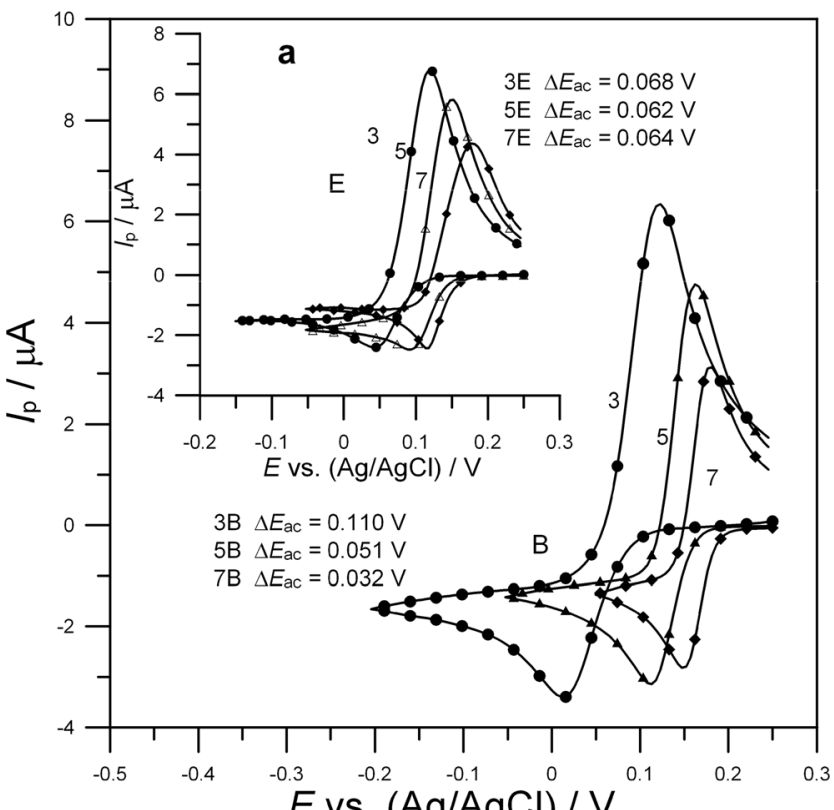

Fig. 3 Cyclic voltammogramme of $110^{-3} \mathrm{~mol} \mathrm{dm}^{-3} \mathrm{Bi}$ (III) in chlorates (VII), where $\mathrm{HClO}_{4}: \mathrm{NaClO}_{4}=1: 4(\boldsymbol{B})$. The concentration of chlorates

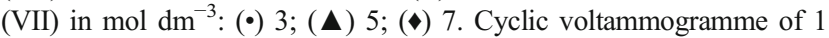
$10^{-3} \mathrm{~mol} \mathrm{dm}{ }^{-3} \mathrm{Bi}$ (III) in chlorates (VII), where $\mathrm{HClO}_{4}: \mathrm{NaClO}_{4}=9: 1$ $(\boldsymbol{E})$. The concentration of chlorates (VII) in $\mathrm{mol} \mathrm{dm}^{-3}:(\bullet) 3 ;(\boldsymbol{\Delta}) 5 ;(\bullet) 7$

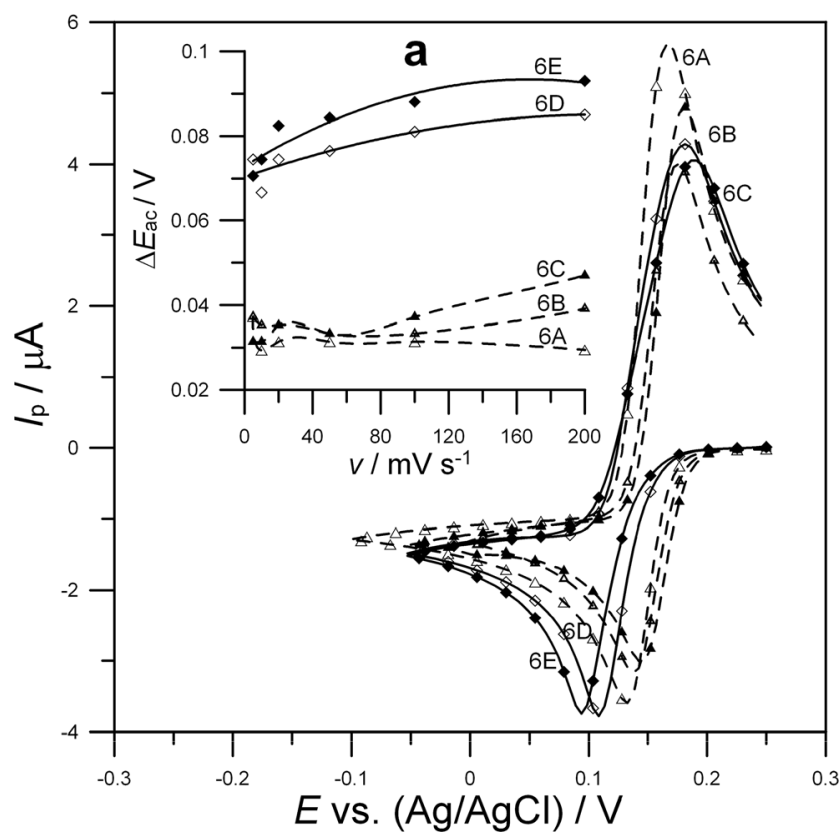

Fig. 4 The cyclic voltammogramme of $110^{-3} \mathrm{~mol} \mathrm{dm}^{-3} \mathrm{Bi}$ (III) in $6 \mathrm{~mol} \mathrm{dm}{ }^{-3}$ chlorates (VII), where $\mathrm{HClO}_{4}: \mathrm{NaClO}_{4}=1: 1$ (一) 6A; $\mathrm{HClO}_{4}: \mathrm{NaClO}_{4}=1: 4(-) 6 \mathrm{~B} ; \mathrm{HClO}_{4}: \mathrm{NaClO}_{4}=1: 9$ (一) $6 \mathrm{C} ; \mathrm{HClO}_{4}$ : $\mathrm{NaClO}_{4}=4: 1(-) 6 \mathrm{D} ; \mathrm{HClO}_{4}: \mathrm{NaClO}_{4}=9: 1(-)$ 6E. The influence of polarisation rate on the difference between the potentials of the anodic and cathodic peaks for the $\mathrm{Bi}(\mathrm{III}) / \mathrm{Bi}(\mathrm{Hg})$ couple in $6 \mathrm{~mol} \mathrm{dm}^{-3}$ chlorates (VII), where $\mathrm{HClO}_{4}: \mathrm{NaClO}_{4}=1: 1(-) 6 \mathrm{~A} ; \mathrm{HClO}_{4}: \mathrm{NaClO}_{4}=1: 4$ (一) 6B; $\mathrm{HClO}_{4}: \mathrm{NaClO}_{4}=1: 9(-) 6 \mathrm{C} ; \mathrm{HClO}_{4}: \mathrm{NaClO}_{4}=4: 1$ (-) 6D; $\mathrm{HClO}_{4}$ : $\mathrm{NaClO}_{4}=9: 1(-) 6 \mathrm{E}$

of the amount of $\mathrm{NaClO}_{4}$ to $\mathrm{HClO}_{4}(6 \mathrm{~A}, 6 \mathrm{~B}, 6 \mathrm{C})$. Instead, in the solutions with the preponderant concentration of chloric (VII) acid in the supporting electrolyte solution (6D, 6E), the shift of the cathodic peaks potentials towards more negative potentials is observed, whereas the anodic peaks are shifted towards the more positive potentials. Such oscillations of the cathodic and anodic peaks potentials in the function of the changes of $\mathrm{NaClO}_{4}$ and $\mathrm{HClO}_{4}$ concentration ratios in the supporting electrolyte suggest the differences in the mechanism of $\mathrm{Bi}$ (III) ions electroreduction, as well as the significant dependence of the active complex structure on the composition of the supporting electrolyte $[3,4]$.

The increase in both $\mathrm{NaClO}_{4}(6 \mathrm{~A}, 6 \mathrm{~B}, 6 \mathrm{C}$ solutions) and $\mathrm{HClO}_{4}(6 \mathrm{D}, 6 \mathrm{E}$ solutions) concentrations results in the increase in the distance between the anodic and cathodic peak potentials $\Delta E_{\mathrm{ac}}$ :

6A $\Delta E_{\mathrm{ac}}=0.029 ; 6 \mathrm{~B} \Delta E_{\mathrm{ac}}=0.036 ; 6 \mathrm{C} \Delta E_{\mathrm{ac}}=0.040 ; 6 \mathrm{D}$ $\Delta E_{\mathrm{ac}}=0.074 ; 6 \mathrm{E} \Delta E_{\mathrm{ac}}=0.094$. This is evidence for the inhibiting effect on the kinetics of the studied electrode process. The increase of the concentration of sodium salt of the chloric (VII) acid against the $\mathrm{HClO}_{4}$ concentration in the supporting electrolyte causes lower effects when comparing with the supporting electrolyte with the bigger amount of chloric (VII) acid compared with its sodium salt. In the solutions of the concentrated electrolytes $\left(4-7 \mathrm{~mol} \mathrm{dm}^{-3}\right)$ of 
chlorates (VII), the number of "free water molecules" decreases in the aftermath of the hydration process. In acid noncomplexing electrolyte solutions, the $\mathrm{Bi}\left(\mathrm{H}_{2} \mathrm{O}\right){ }_{9}{ }^{3+}$ ion is described by the very low rate of hydration water release. Thereupon the cumulative electrode process will also be consisted of the chemical stages leading to the labilisation of $\mathrm{Bi}\left(\mathrm{H}_{2} \mathrm{O}\right){ }_{9}{ }^{3+}$ hydration shell [8]. The dependence plot of the potential difference of the anodic and cathodic peaks $\Delta E_{\mathrm{ac}}$ on the electrode polarisation rate $(v)$ (Fig. $4 \mathrm{a})$ confirms these assumptions. In all the solutions of the supporting electrolyte $(6 \mathrm{~A}, 6 \mathrm{~B}, 6 \mathrm{C}, 6 \mathrm{D}, 6 \mathrm{E})$, the slight changes of $\Delta E_{\mathrm{ac}}$ at low polarisation rates $\left(5-100 \mathrm{mv} \mathrm{s}^{-1}\right)$ are observed, which expresses the fact that the stage controlling the electroreduction rate of $\mathrm{Bi}$ (III) ions is the chemical reaction. This is certainly the reaction of $\mathrm{Bi}$ (III) ions dehydration mentioned before. The studies of Eyring [9] and Zelič [10] et al., concerning the rate of In (III) ions electroreduction in the solutions of noncomplexing electrolytes, confirm our assumptions.

It should be noticed as well that in the solutions $6 \mathrm{~A}$, $6 \mathrm{~B}, 6 \mathrm{C}$ with the preponderant amount of $\mathrm{NaClO}_{4}$, the shape of $\Delta E_{\mathrm{ac}}=\mathrm{f}(v)$ (Fig. 4a) is completely different than in the solutions $6 \mathrm{D}, 6 \mathrm{E}$, where the amount of chloric (VII) acid prevails. Such behaviour suggests differences in the electrode mechanism [4].

The research by Nazmutdinov et al. [11, 12], in which the quantum mechanical theory was used to describe the reduction of multivalent ions (e.g. In (III)), suggests the existence of the hydrolysed forms of Bi (III) ions in aqueous solutions. Moreover, the hydrolised forms of Bi (III) ions can be more active as compared with $\mathrm{Bi}$ (III) aquacomplexes [12].

In the case of $\left[\mathrm{Bi}\left(\mathrm{H}_{2} \mathrm{O}\right)_{9}\right]^{+3}$, the acceptor molecular orbital is localised mostly on the $\mathrm{Bi}$ atom, which leads to relative slight dependence of the activation energy values on the first step of electron transfer. However, as the case of Bi (III) aquahydroxocomplex, a more strong decreasing the activation energy values starting from certain region of distances was observed as compared with $\left[\mathrm{Bi}\left(\mathrm{H}_{2} \mathrm{O}\right)_{9}\right]^{+3}[11,12]$. This adiabatic effect explains a high electrochemical activity of the $\mathrm{Bi}$ (III) aquahydroxocomplexes which may compete with Bi (III) aquacomplexes in electroreduction and affect the changes in the mechanism of the process.

The formal potentials $E_{\mathrm{f}}^{0}$ and the kinetic parameters $\alpha n_{\alpha}$ and $k_{\mathrm{s}}$ (Table 1 ) were determined from the chronovoltammetric measurements.

The results of the parameters correlation lead to the statement that the changes in the amount of chloric (VII) acid against the amount of its sodium salt in the supporting electrolytes of the low water activity have a significant influence on the rate of $\mathrm{Bi}$ (III) ions electroreduction, particularly for the solutions A, B, C. It should be noticed that with the increase of the concentrations of both $\mathrm{NaClO}_{4}(\mathrm{~A}, \mathrm{~B}, \mathrm{C})$ and $\mathrm{HClO}_{4}$ (D, $\mathrm{E}$ ) in the solution of supporting electrolyte, the standard rate constants $k_{\mathrm{s}}$ of $\mathrm{Bi}$ (III) ions electroreduction decrease. The direction of changes of the $E_{\mathrm{f}}^{0}$ values shift suggests the differences in the mechanism of $\mathrm{Bi}$ (III) ions electroreduction in the solutions A, B, C of chlorates (VII), when comparing them with the solutions $\mathrm{D}, \mathrm{E}$.

\section{The Impedance Measurements}

The values of apparent rate constants $k_{\mathrm{f}}$ were obtained based on charge-transfer resistance [10] as a function of the potential. The increased values of the charge-transfer resistance $R_{\mathrm{a}_{\min }}$ determined at the formal potential (Table 2), clearly demonstrate the inhibitory effect of the supporting electrolyte (D, E).

It can be seen, however, that the distinct decrease of the charge-transfer resistance values, with the increase of the chlorates (VII) concentrations for all the solutions examined of chlorates (VII) (A, B, C, D, E), confirms the catalytic influence of the decrease of water activity on the process of $\mathrm{Bi}$ (III) ions electroreduction.

The dependences $\ln k_{\mathrm{f}}=\mathrm{f}(E)$ for all the chlorates concentrations studied are not linear (Fig. 5), and the curves' slopes change with the change of the potential and chlorates (VII) concentration. Some characteristics of $k_{\mathrm{f}}$ change in the function of the potential points at the existence of the multistage process of Bi (III) ions electroreduction [13-19]. It also
Table 1 The values of formal potentials $\left(E_{\mathrm{f}}^{0}\right)$, cathodic transition coefficients $\left(\alpha n_{\alpha}\right)$, standard rate constants $\left(k_{\mathrm{s}}\right)$ of electroreduction of 1 $10^{-3} \mathrm{~mol} \mathrm{dm}^{-3} \mathrm{Bi}(\mathrm{III})$ in chlorates (VII) solutions of concentration ratio
$\mathrm{HClO}_{4}: \mathrm{NaClO}_{4}(1: 1)$ solution $\mathrm{A},(1: 4)$ solution $\mathrm{B},(1: 9)$ solution $\mathrm{C},(4: 1)$ solution $\mathrm{D},(9: 1)$ solution $\mathrm{E}$

\begin{tabular}{|c|c|c|c|c|c|c|c|c|c|c|c|c|}
\hline \multirow[t]{2}{*}{ Chlorate (VII) } & \multicolumn{3}{|c|}{$2 \mathrm{~mol} \mathrm{dm}^{-3}$} & \multicolumn{3}{|c|}{$4 \mathrm{~mol} \mathrm{dm}^{-3}$} & \multicolumn{3}{|c|}{$6 \mathrm{~mol} \mathrm{dm}^{-3}$} & \multicolumn{3}{|c|}{$7 \mathrm{~mol} \mathrm{dm}^{-3}$} \\
\hline & $E_{\mathrm{f}}^{0} / \mathrm{V}$ & $\alpha n_{\alpha}$ & $10^{4} k_{\mathrm{s}} / \mathrm{cm} \mathrm{s}^{-1}$ & $E_{\mathrm{f}}^{0} / \mathrm{V}$ & $\alpha n_{\alpha}$ & $10^{4} k_{\mathrm{s}} / \mathrm{cm} \mathrm{s}^{-1}$ & $E_{\mathrm{f}}^{0} / \mathrm{V}$ & $\alpha n_{\alpha}$ & $10^{4} k_{\mathrm{s}} / \mathrm{cm} \mathrm{s}^{-1}$ & $E_{\mathrm{f}}^{0} / \mathrm{V}$ & $\alpha n_{\alpha}$ & $10^{4} k_{\mathrm{s}} / \mathrm{cm} \mathrm{s}^{-1}$ \\
\hline A & 0.102 & 0.28 & 1.43 & 0.125 & 0.40 & 24.4 & 0.150 & 0.70 & 61.7 & 0.160 & 0.74 & 100.3 \\
\hline B & 0.097 & 0.33 & 1.50 & 0.131 & 0.41 & 13.5 & 0.157 & 0.60 & 46.6 & 0.158 & 0.69 & 90.6 \\
\hline $\mathrm{C}$ & 0.095 & 0.35 & 1.52 & 0.125 & 0.40 & 12.4 & 0.158 & 0.54 & 27.1 & 0.168 & 0.60 & 85.1 \\
\hline D & 0.098 & 0.31 & 1.52 & 0.111 & 0.39 & 10.4 & 0.143 & 0.40 & 10.9 & 0.153 & 0.43 & 9.91 \\
\hline E & 0.102 & 0.27 & 1.28 & 0.110 & 0.39 & 7.13 & 0.140 & 0.39 & 6.91 & 0.146 & 0.40 & 6.61 \\
\hline
\end{tabular}


Table 2 The values of formal potentials of electroreduction of 1 $10^{-3} \mathrm{~mol} \mathrm{dm}{ }^{-3} \mathrm{Bi}(\mathrm{III})$ in chlorates (VII) solutions of concentration ratio $\mathrm{HClO}_{4}: \mathrm{NaClO}_{4}$ : (1:1) solution A, (1:4) solution $\mathrm{B},(1: 9)$ solution $\mathrm{C},(4: 1)$ solution $\mathrm{D},(9: 1)$ solution $\mathrm{E}$, as well as the values of the charge transfer

\begin{tabular}{|c|c|c|c|c|c|c|}
\hline \multirow[t]{2}{*}{ Chlorate (VII) } & \multicolumn{2}{|c|}{$2 \mathrm{~mol} \mathrm{dm}^{-3}$} & \multicolumn{2}{|c|}{$4 \mathrm{~mol} \mathrm{dm}^{-3}$} & \multicolumn{2}{|c|}{$6 \mathrm{~mol} \mathrm{dm}^{-3}$} \\
\hline & $E_{\mathrm{f}}^{0} / \mathrm{V}$ & $R_{\mathrm{a}_{\min }} / \Omega \mathrm{cm}^{2}$ & $E_{\mathrm{f}}^{0} / \mathrm{V}$ & $R_{\mathrm{a}_{\min }} / \Omega \mathrm{cm}^{2}$ & $E_{\mathrm{f}}^{0} / \mathrm{V}$ & $R_{\mathrm{a}_{\min }} / \Omega \mathrm{cm}^{2}$ \\
\hline A & 0.102 & 224.3 & 0.125 & 28.96 & 0.150 & 2.72 \\
\hline B & 0.097 & 242.9 & 0.131 & 56.9 & 0.157 & 6.94 \\
\hline $\mathrm{C}$ & 0.095 & 252.1 & 0.125 & 74.2 & 0.158 & 11.98 \\
\hline $\mathrm{D}$ & 0.098 & 253.1 & 0.111 & 89.4 & 0.143 & 74.0 \\
\hline E & 0.102 & 249.1 & 0.110 & 139.3 & 0.140 & 117.6 \\
\hline
\end{tabular}

resistance $\left(R_{\mathrm{a}_{\min }}\right)$ Bi (III) electroreduction in the studied systems determined at the formal potential confirms the earlier observed regularity of the differences in the mechanism of $\mathrm{Bi}$ (III) ions electroreduction apropos the change of $\mathrm{NaClO}_{4}: \mathrm{HClO}_{4}$ ratio in the supporting electrolyte. Assuming that the process of $\mathrm{Bi}$ (III) electroreduction is multistaged, and the transfer of individual electrons proceeds consecutively, then at the less positive potentials, the process rate is controlled by the transfer of the first electron (Fig. 5) [13-15]. It occurs, presumably, in the outer Helmholtz plane or within the one water molecule from the electrode surface [20-22].

Similar conclusions regarding the $\left[\mathrm{In}\left(\mathrm{H}_{2} \mathrm{O}\right)_{6}\right]^{+3}$ electroreduction were made earlier in Ref [23] using a quantum mechanical theory.

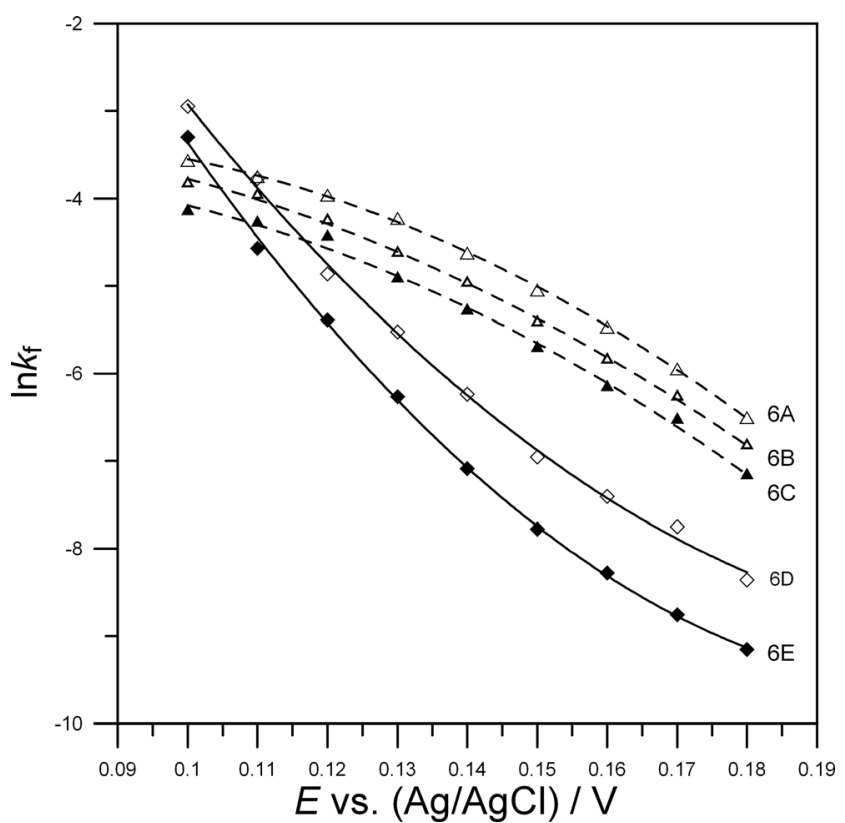

Fig. 5 The dependence of rate constants of $110^{-3} \mathrm{~mol} \mathrm{dm}^{-3} \mathrm{Bi}$ (III) electroreduction in $6 \mathrm{~mol} \mathrm{dm}^{-3}$ chlorates (VII), where $\mathrm{HClO}_{4}: \mathrm{NaClO}_{4}=$ $1: 1(-) 6 \mathrm{~A} ; \mathrm{HClO}_{4}: \mathrm{NaClO}_{4}=1: 4(-)$ 6 $; \mathrm{HClO}_{4}: \mathrm{NaClO}_{4}=1: 9$ (一) $6 \mathrm{C}$; $\mathrm{HClO}_{4}: \mathrm{NaClO}_{4}=4: 1(-) 6 \mathrm{D} ; \mathrm{HClO}_{4}: \mathrm{NaClO}_{4}=9: 1(-) 6 \mathrm{E}$ on the electrode potential
The inner sphere contribution to the total reorganisation energy for $\left[\mathrm{In}\left(\mathrm{H}_{2} \mathrm{O}\right)_{6}\right]^{+3}$ is larger when compared with In (III) aquahydroxocomplex, since the solvent reorganisation is practically the same for both species. The electrodereactant orbital overlap is stronger for $\left[\mathrm{In}\left(\mathrm{H}_{2} \mathrm{O}\right)_{5} \mathrm{OH}\right]^{+2}$. Such findings agree with the structure of acceptor orbitals explored for both complex ions. The first electron transfer was shown to be rate controlling [23].

\section{Conclusions}

The described studies confirmed unequivocally the inversely proportional dependence of the rate of $\mathrm{Bi}$ (III) ions electroreduction on water activity [4]. The rate of Bi (III) ions electroreduction increases with the decrease of water activity [4].

Significant changes in the kinetics of the $\mathrm{Bi}$ (III) ions electroreduction process apropos the change of $\mathrm{HClO}_{4}$ : $\mathrm{NaClO}_{4}$ ratio in the solutions $\left(4-7 \mathrm{~mol} \mathrm{\textrm {dm } ^ { - 3 }}\right.$ ) of chlorates (VII) were found. The increase of the concentration of chloric acid sodium salt, as well as the chloric (VII) acid alone within the particular concentration of the supporting electrolyte, inhibits the process of $\mathrm{Bi}$ (III) ions electroreduction. It should be associated with the reorganisation of the structure of the double layer connected with the slow dehydration inhibited by $\mathrm{ClO}-\frac{-}{4}$ ions. Analysing water activity in the studied solutions of chloric (VII) acid and sodium salt of chloric (VII) acid [3], it should be mentioned that the increase of $\mathrm{NaClO}_{4}$ concentration results in the changes of water activity from 0.965 in $1 \mathrm{~mol} \mathrm{dm}^{-3} \mathrm{NaClO}_{4}$ to 0.628 in $7 \mathrm{~mol} \mathrm{dm}^{-3} \mathrm{NaClO}_{4}$; whereas the change of $\mathrm{HClO}_{4}$ concentration from $1 \mathrm{~mol} \mathrm{dm}^{-3}$ to $7 \mathrm{~mol} \mathrm{dm}^{-3}$ causes the decrease of water activity from 0.962 to 0.325 . Such behaviour explains the change of the kinetics and presumably the mechanism of the process examined. 
The question is raised, if the replacement of $\mathrm{Na}^{+}$ions with $M e^{+n}$ ions, where $n>1$, in the supporting electrolyte, will it lead to similar effects?

Open Access This article is distributed under the terms of the Creative Commons Attribution License which permits any use, distribution, and reproduction in any medium, provided the original author(s) and the source are credited.

\section{References}

1. A. Ciszewski, M. Baraniak, "Aktywność chemiczna i elektrochemiczna pierwiastków w środowisku wody”,(Wyd. Politechniki Poznańskiej, Poznań 2006)

2. S. Komorsky-Lovrič, M. Lovrič, M. Branica, Indian. J. Chem. 29A, 435 (1990)

3. S. Komorsky-Lovrič, M. Lovrič, M. Branica, J. Electrochem. Soc. 140, 1850 (1993)

4. A. Nosal-Wiercińska, Electrochim. Acta. 55, 5917 (2010)

5. R.S. Nicholson, Anal. Chem. 37, 1351 (1965)
6. Z. Galus, "Electroanalytical methods of determination of physicochemical constants", (in Polish), (PWN, Warsaw, 1979)

7. E. Lust, R. Truu, K. Lust, Russian. J. Electrochem. 36, 1349 (2000)

8. S. Komorsky-Lovrič, M. Lovrič, M. Branica, J. Electroanal. Chem. 241, 329 (1988)

9. E.M. Eyring, J.D. Owen, J. Phys. Chem. 74, 1825 (1970)

10. M. Zelič, M. Mlakar, M. Branica, Anal. Chim. Acta. 289, 289 (1994)

11. R.R. Nazmutdinov, W. Schmickler, A.M. Kuznetsov, Chem. Phys. 310, 257 (2005)

12. R.R. Nazmutdinov, T.T. Zinkicheva, G.A. Tsirlina, Z.V. Kuz'minova, Electrochim. Acta. 50, 4888 (2005)

13. R. Andreu, M. Sluyters-Rehbach, A.G. Remijnse, J.H. Sluyters, J. Electroanal. Chem. 134, 101 (1982)

14. J. Nieszporek, J. Electroanal. Chem. 662, 407 (2011)

15. J. Nieszporek, J. Electroanal. Chem. 706, 108 (2013)

16. J. Nieszporek, K. Dagci, Electrochim. Acta. 125, 473 (2014)

17. A. Nosal-Wiercińska, J. Electroanal. Chem. 654, 66 (2011)

18. A. Nosal-Wiercińska, J. Electroanal. Chem. 681, 103 (2012)

19. A. Nosal-Wiercińska, Electroanalysis. 26, 1013 (2014)

20. S. Chibowski, M. Wiśniewska, Adsorp. Sci. Techno. 19, 409 (2001)

21. S. Chibowski, M. Wiśniewska, T. Urban, Adsorption. 16, 321 (2010)

22. G. Dalmata, Electroanalysis. 17, 789 (2005)

23. M.D. Bronshtein, R.R. Nazmutdinov, W. Schmickler, Chem. Phys. Lett. 399, 307 (2004) 